\title{
Clinical outcome following coronary angioplasty in dialysis patients: a case-control study in the era of coronary stenting
}

\author{
C Le Feuvre, G Dambrin, G Helft, F Beygui, M Touam, J P Grünfeld, A Vacheron, \\ J P Metzger
}

\begin{abstract}
Background-Balloon coronary angioplasty has been reported to be ineffective in patients treated for end stage renal disease because of a high restenosis rate.

Objective-To compare the clinical outcome following coronary angioplasty with provisional stenting in dialysis versus non-dialysis patients.

Design-A case-control study.

Patients-Of 1428 consecutive patients who underwent coronary angioplasty, 100 (7\%) were being treated for end stage renal disease. These were compared with 100 control patients matched for age, sex, coronary lesions, presence of diabetes mellitus, and rate of coronary stenting (40\%).

Main outcome measures-In-hospital and one year clinical outcome.

Results-The rates of procedural success (90\% v 93\%), in-hospital mortality ( $1 \% v 0 \%$ ), stent thrombosis $(0 \% v 0 \%)$, and Q wave myocardial infarction $(0 \% v 1 \%)$ were similar in dialysis and non-dialysis patients. One year clinical outcome after coronary angioplasty was similar in the two groups in terms of clinical restenosis $(31 \% v 28 \%)$ and myocardial infarction $(6 \% v 2 \%)$, but cardiac death was more common in dialysed patients $(11 \% v 2 \%, \mathrm{p}<0.03)$.

Conclusions-Dialysis does not increase the risk of clinical restenosis after coronary angioplasty with provisional stenting. Coronary angioplasty is a safe and effective therapeutic procedure in selected dialysis patients with culprit lesions accessible to stenting. However, the one year survival is reduced in this high risk population.
\end{abstract}

(Heart 2001;85:556-560)

Keywords: renal disease; angioplasty; stents; restenosis

Cardiovascular complications remain the leading cause of mortality among patients with end stage renal disease on haemodialysis. Cardiovascular disease accounts for half the total mortality, ${ }^{1}$ and myocardial infarction for half the cardiac deaths. ${ }^{2}$ The overall mortality after myocardial infarction among 34189 dialysis patients identified from the US Renal Data System database was $59 \%$ at one year and $90 \%$ at five years. ${ }^{3}$ Disappointing results have been obtained with balloon coronary angioplasty (PTCA) in these patients, with a high incidence of short and long term complications. Many studies have shown an unfavourable outcome of PTCA compared with coronary artery bypass grafting (CABG) in dialysis patients. ${ }^{4-11}$ The main reason for this was the high rate of repeat revascularisation for restenosis, which occurs after balloon angioplasty in two thirds of dialysis patients. Thus balloon angioplasty has been reported to be ineffective in dialysis patients. ${ }^{812}$ According to many investigators, coronary bypass surgery is the preferred treatment in dialysis patients with severe angina and extensive coronary artery disease. $^{6-912}$

Whereas coronary stenting has been shown to reduce acute closure and six month restenosis in non-dialysis patients, ${ }^{13}{ }^{14}$ few data on angioplasty and stenting are available in dialysis patients. ${ }^{15}$ The purpose of the current study was to determine the influence of dialysis on in-hospital and mid-term outcome following coronary angioplasty with provisional stenting In-hospital and one year clinical outcome were compared between dialysis and control patients matched for clinical and angiographic characteristics.

\section{Methods}

STUDY POPULATION

Between January 1995 and April 1999, 1428 patients (1616 coronary lesions) underwent coronary angioplasty at the cardiovascular department of Necker Hospital; 100 patients (7\%) had end stage renal disease with dialysis for at least 90 days before the angioplasty. Coronary angioplasty was performed for silent myocardial ischaemia detected before renal transplantation in seven dialysis patients (7\%). Baseline clinical and angiographic characteristics, procedural results, and hospital complications were entered prospectively into a computerised database. Dialysis patients were compared with 100 control patients with normal renal function matched for age, sex, coronary lesions, presence of diabetes mellitus, and rate of coronary stenting $(40 \%)$. Control patients were randomly selected from among 1328 non-dialysis patients. All patients were treated and studied after giving informed consent.

CORONARY ANGIOPLASTY AND STENTING PTCA was performed using standard techniques and supplementary treatment, as described previously. ${ }^{16}$ All patients underwent left 
Table 1 Clinical baseline characteristics

\begin{tabular}{lll}
\hline & $\begin{array}{l}\text { Dialysis } \\
\text { patients } \\
(n=100)\end{array}$ & $\begin{array}{l}\text { Non-dialysis } \\
\text { patients } \\
(n=100)\end{array}$ \\
\hline Age (years) & $59(11)$ & $59(11)$ \\
Male sex & $77 \%$ & $77 \%$ \\
Hypertension & $82 \%$ & $37 \% \star$ \\
Smoking history & $42 \%$ & $60 \% \dagger$ \\
Total cholesterol (mmol/l) & $6.1(1.3)$ & $5.5(0.8) \dagger$ \\
Triglycerides (mmol/l) & $1.9(1.5)$ & $1.5(0.8)$ \\
Diabetes mellitus & $23 \%$ & $23 \%$ \\
Unstable angina & $50 \%$ & $54 \%$ \\
Prior MI & $29 \%$ & $41 \%$ \\
Prior CABG & $11 \%$ & $5 \%$ \\
Medical treatment & & \\
$\quad$ B Blockers & $62 \%$ & $66 \%$ \\
$\quad$ Calcium antagonists & $51 \%$ & $39 \%$ \\
Nitrates & $35 \%$ & $53 \%$ \\
Lipid lowering drugs & $46 \%$ & $55 \%$ \\
Statins & $41 \%$ & $43 \%$
\end{tabular}

Values are per cent or mean (SD).

Dialysis $v$ non-dialysis patients: ${ }^{\star} \mathrm{p}<0.0001 ; \mathrm{tp}<0.01$.

$\mathrm{CABG}$, coronary artery bypass grafting; MI, myocardial infarction.

ventriculography and coronary angiography in multiple projections. The arterial access route was femoral in all cases. A 6 French guide catheter was used in 65 dialysis patients $(65 \%)$ and in 62 non-dialysis patients (62\%) (NS). A 7 French guide catheter was used in the remaining patients. All patients had been given aspirin $250 \mathrm{mg} /$ day at least three hours before, and a bolus of heparin (100 IU/kg) just before angioplasty.

Stents were inserted either electively, or as a bailout, or following a suboptimal result after balloon angioplasty, with residual stenosis exceeding $30 \%$. The type of stent was similar in dialysis and non-dialysis patients. GFX (AVE), Nir (Scimed), Tenax (Biotronik), PalmazSchatz (Johnson and Johnson) stents were implanted in $31 \%, 27 \%, 21 \%$, and $10 \%$ of the patients, respectively; other tubular or coil stents were used in $8 \%$ and $3 \%$ of the patients. Procedural success was defined as a diameter stenosis reduction of $>20 \%$ with a residual stenosis of $<50 \%$ in the absence of major complications (including death, myocardial infarction, and need for emergency surgery). A stent-like result was defined as residual diameter stenosis of $<30 \%$. Myocardial infarction was defined by an increase in serum creatine phosphokinase concentration to more than three times the upper limit of normal, along with the presence of detectable creatine phosphokinase MB isoenzyme. Vascular complications included haematoma requiring a blood transfusion, and false aneurysm requiring surgical repair or prolonged compression. Post-stent antithrombotic treatment included ticlopidine $(500 \mathrm{mg} /$ day), started immediately after the procedure and continued for four weeks, and aspirin $(100 \mathrm{mg} /$ day for four weeks and then $250 \mathrm{mg} /$ day). Five dialysis and two non-dialysis patients with refractory unstable angina also received abciximab treatment during coronary angioplasty (NS).

ANGIOGRAPHIC ANALYSES

Quantitative angiographic analyses were performed digitally using computer assisted calipers (DCI Philips, CAAS System, Eindhoven, Netherlands). The degree of stenosis before
Table 2 Angiographic baseline characteristics

\begin{tabular}{lll}
\hline & $\begin{array}{l}\text { Dialysis } \\
\text { patients } \\
(n=100)\end{array}$ & $\begin{array}{l}\text { Non-dialysis } \\
\text { patients } \\
(n=100)\end{array}$ \\
\hline LVEF (\%) & $63(16)$ & $64(16)$ \\
Multivessel disease & $49 \%$ & $49 \%$ \\
Site of angioplasty & $(\mathrm{n}=120)$ & $\begin{array}{l}(\mathrm{n}=120) \\
\text { LAD }\end{array}$ \\
LCx & $40 \%$ & $41 \%$ \\
RCA & $25 \%$ & $23 \%$ \\
Venous graft & $32 \%$ & $31 \%$ \\
Type of lesion & $3 \%$ & $4 \%$ \\
Restenosis & $15 \%$ & $17 \%$ \\
Chronic occlusion & $6 \%$ & $8 \%$ \\
Thrombus & $5 \%$ & $6 \%$ \\
Bifurcation/ostial & $12 \%$ & $11 \%$ \\
Eccentricity & $55 \%$ & $54 \%$ \\
Calcification & $20 \%$ & $8 \% \star$ \\
Indication for stenting & & \\
Bailout & $9 \%$ & $11 \%$ \\
Suboptimal result & $76 \%$ & $76 \%$ \\
Elective & $15 \%$ & $13 \%$
\end{tabular}

Values are mean (SD) or per cent.

Dialysis $v$ non-dialysis patients: ${ }^{\star} \mathrm{p}<0.05$

$\mathrm{LAD}$, left anterior descending coronary artery; LCx, left circumflex coronary artery; LVEF, left ventricular ejection fraction; RCA, right coronary artery.

and after angioplasty was measured after intracoronary injection of Sin-1 (linsidomine, $1 \mathrm{mg}$ ) in the view showing the most severe stenosis, and expressed as the minimum lumen diameter and the linear per cent lumen diameter reduction, using the average diameter of the nearest proximal and distal normal segments as the reference.

FOLLOW UP

Long term follow up data were obtained by serial telephone interviews. Late clinical events were corroborated by primary source documentation. Control angiography was restricted to patients with recurrence of limiting symptoms or severe documented ischaemia or both. Restenosis was diagnosed when a narrowing of $\geqslant 50 \%$ of vessel diameter was found at the site of the previous dilatation. Clinical restenosis was defined as recurrent myocardial ischaemia related to angiographic restenosis. The indications for a new revascularisation procedure were either restenosis at a site of previous dilatation or the appearance of a new significant coronary artery stenosis not present on the initial angiogram.

\section{STATISTICAL ANALYSIS}

Categorical data are presented as per cent frequencies. Continuous variables are presented as mean (SD). Univariate analyses were performed using the $\chi^{2}$ test for categorical data and analysis of variance for continuous variables. Multiple logistic regression and stepwise logistic regression analyses were performed in the standard manner. A probability value of $\mathrm{p}<0.05$ was considered significant.

\section{Results}

CLINICAL AND ANGIOGRAPHIC BASELINE

CHARACTERISTICS

Dialysis patients were more often hypertensive and less likely to smoke than non-dialysis patients (table 1). Coronary lesions were similar among the groups, except for calcification which was more common in dialysis patients 
Table 3 Procedural results

\begin{tabular}{lll}
\hline & $\begin{array}{l}\text { Dialysis } \\
\text { patients } \\
(n=100)\end{array}$ & $\begin{array}{l}\text { Non-dialysis } \\
\text { patients } \\
(n=100)\end{array}$ \\
\hline Before PTCA & 120 & 120 \\
$\quad$ PTCA sites (n) & $2.9(0.5)$ & $3.0(0.5)$ \\
Reference diameter (mm) & $0.8(0.4)$ & $0.7(0.4)$ \\
MLD (mm) & $71(14)$ & $74(14)$ \\
Diameter stenosis (\%) & $11(5)$ & $11(6)$ \\
$\quad$ Lesion length (mm) & & \\
Procedural success & $90 \%$ & $93 \%$ \\
Per patient & $91 \%$ & $94 \%$ \\
$\quad$ Per lesion & 109 & 113 \\
After successful PTCA & $2.4(0.6)$ & $2.3(0.7)$ \\
$\quad$ PTCA sites (n) & $17(12)$ & $18(12)$ \\
MLD (mm) & $40 \%$ & $40 \%$ \\
$\quad$ Diameter stenosis (\%) & $11(3)$ & $13(6)$ \\
Coronary stenting & $11(2)$ & $12(3)$ \\
$\quad$ Stent length (mm) & & \\
Stent inflation pressure (atm) &
\end{tabular}

Values are mean (SD) or per cent.

MLD, minimum lumen diameter; PTCA, percutaneous transluminal coronary angioplasty.

Table 4 Complications during hospital admission

\begin{tabular}{lll}
\hline & $\begin{array}{l}\text { Dialysis } \\
\text { patients } \\
(n=100)\end{array}$ & $\begin{array}{l}\text { Non-dialysis } \\
\text { patients } \\
(n=100)\end{array}$ \\
\hline Major cardiac events & 6 & 2 \\
Death & 2 & 0 \\
Q wave MI & 0 & 1 \\
Non-Q wave MI & 4 & 1 \\
Urgent CABG & 0 & 0 \\
Urgent re-PTCA & 0 & 1 \\
Subacute thrombosis & 0 & 1 \\
Vascular complications & 4 & 2 \\
Haematoma requiring blood & 3 & 1 \\
$\quad$ transfusion & 1 & 1 \\
False aneurysm & & \\
\hline
\end{tabular}

Values are per cent.

(table 2). Quantitative measurements preprocedure showed that the reference vessel size was identical in the two groups.

PROCEDURAL RESULTS AND IN-HOSPITAL COMPLICATIONS

The rates of procedural success per lesion were similar in the two groups (table 3). The main cause of procedural failure in dialysis patients was extensive tortuosities and calcifications (nine of 12), whereas the main cause of procedural failure in non-dialysis patients was chronic occlusion (six of seven). Residual stenosis after successful PTCA was similar in dialysis and non-dialysis patients (table 3 ). In the group as a whole, stepwise logistic regression identified chronic occlusion as the only predictor of procedural failure $(\mathrm{p}<0.001)$.

The rates of in-hospital mortality $(2 \% v$ $0 \%)$, stent thrombosis $(0 \% v 1 \%)$, and $\mathrm{Q}$ wave myocardial infarction ( $0 \% v 1 \%)$ were similar in dialysis and non-dialysis patients. Non-Q wave myocardial infarction occurred in four non-dialysis patients $(4 \%)$ and one dialysis patient $(1 \%)$ (table 4 ). Multivariate analysis failed to identify any independent predictors of in-hospital complications.

Haematoma requiring prolonged decubitus was more common in dialysis patients $(13 \% v$ $4 \%, \mathrm{p}=0.06)$, whereas the numbers of false aneurysms and haematomas requiring blood transfusion were similar in the two groups (table 4).
Table 5 Late clinical follow up

\begin{tabular}{lcc}
\hline & $\begin{array}{l}\text { Dialysis } \\
\text { patients }\end{array}$ & $\begin{array}{l}\text { Non-dialysis } \\
\text { patients }\end{array}$ \\
\hline Any event & 42 & 37 \\
Cardiac death & 11 & $2^{\star}$ \\
Non-fatal MI & 6 & 2 \\
Any revascularisation & 36 & 33 \\
$\quad$ For restenosis & 31 & 28 \\
$\quad$ For progression of disease & 5 & 5 \\
\hline
\end{tabular}

Values are per cent.

${ }^{\star} \mathrm{p}<0.03$ for dialysis $v$ non-dialysis patients.

LONG TERM OUTCOME

One year clinical follow up was available in all dialysis patients and 99 of the 100 non-dialysis patients. The overall coronary event rate was similar in the two groups in terms of clinical restenosis $(31 \%$ v $28 \%)$ and myocardial infarction $(6 \% v 2 \%)$, but cardiac death was more frequent in dialysis patients $(11 \% v 2 \%$, $\mathrm{p}<0.03$ ) (table 5). In dialysis patients, the rates of cardiac death $(7 \% \quad v \quad 13 \%)$ and non-fatal myocardial infarction $(7 \% v 5 \%)$ were similar after coronary stenting and after balloon angioplasty with stent-like results. In the group as a whole, stepwise logistic regression identified dialysis as the only predictor of cardiac death $(\mathrm{p}<0.01)$. Repeat revascularisation for restenosis was needed by 31 dialysis patients $(31 \%)$ and 28 non-dialysis patients $(28 \%)$ (NS). The rate of repeat revascularisation for restenosis after balloon angioplasty with stent-like results was similar in dialysis and non-dialysis patients (32\% v 33\%). Repeat revascularisation for restenosis after coronary stenting was needed by 12 dialysis patients (30\%) and eight non-dialysis patients (20\%) (NS).

\section{Discussion}

In this study, relative to non-dialysis patients, dialysis patients had: a high and similar procedural success rate; no subacute thrombosis; a similar target vessel revascularisation rate; and a higher cardiac death rate during one year of follow up.

PTCA WITH PROVISIONAL STENTING IN DIALYSIS PATIENTS

In this large series of consecutive patients treated with PTCA, the rate of procedural success was high and similar in dialysis and non-dialysis patients. The rates of death, Q wave myocardial infarction, and urgent repeat revascularisation were low and similar in the two groups. This reflects careful selection of dialysis patients with coronary lesions suitable for angioplasty and accessible to stenting. Our results illustrate the benefits of provisional coronary stenting in patients with suboptimal results after balloon angioplasty. These results are encouraging in comparison with previously reported rates of procedural mortality after balloon angioplasty and bypass surgery in dialysis patients. Herzog identified 5473 patients undergoing balloon angioplasty and 6798 patients undergoing coronary artery bypass surgery from 1978 to 1994 in the US Renal Data System database. ${ }^{4}$ In-hospital mortality was $5.1 \%$ for angioplasty and $14.5 \%$ for 
surgery. Similar unfavourable results of balloon angioplasty have been reported in many single centre series, with in-hospital complication rates ranging from $17-43 \% .^{5-11}$ The high rate of myocardial infarction after angioplasty in dialysis patients can be explained by the greater likelihood of coronary calcification related to secondary hyperparathyroidism, and by an increased prothrombotic risk leading to fibrin and platelet deposition. ${ }^{17}$ Activation of plasma coagulation systems following contact with haemodialysis membranes, and platelet hyperaggregability with decreased responsiveness to prostacyclin, have been reported in dialysis patients. ${ }^{18}$ In our series, only five dialysis patients $(5 \%)$ received abciximab treatment, whereas coronary angioplasty was performed for unstable angina in half the dialysis patients. A reduced rate of myocardial infarction after angioplasty in dialysis patients may well be obtained by more extensive use of abciximab. ${ }^{19}$ In a review of single centre cardiac surgery series in dialysis patients, Ko and colleagues reported that the operative mortality was between $8 \%$ and $9 \% .{ }^{20}$ Haemorrhagic and infectious complications also occur more often in dialysis patients than in non-dialysis patients.

CLINICAL RESTENOSIS AFTER ANGIOPLASTY WITH PROVISIONAL STENTING IN DIALYSIS PATIENTS

In our series the repeat revascularisation rate for restenosis was similar in dialysis and non-dialysis patients. This suggests that dialysis does not affect the clinical restenosis rate when coronary stenting is performed, or when a stent-like result is obtained after balloon angioplasty. The rate was half that reported previously, which has ranged from $47-81 \% .^{9-15}$ In the study by Schoebel and colleagues, ${ }^{5}$ the six month clinical restenosis rate was $65 \%$ in dialysis patients, compared with 37 (9)\% following balloon angioplasty $(v 21(10) \%$ in our study). This suggests that residual stenosis is the main predictive factor of restenosis after PTCA, in accordance with previous studies. ${ }^{21-23}$

In our study dialysis patients with stent-like results had the same clinical restenosis rate as dialysis patients with coronary stenting. However, owing to the small number of patients, this needs to be confirmed in a larger prospective study. In the Benestent II study (second Belgium-Netherlands stent study), which included non-dialysis patients, stent-like results obtained with balloon angioplasty were less expensive than a strategy of elective stenting, but remain less effective, with a $6 \%$ difference in event-free survival. ${ }^{24}$ However, our results suggest that PTCA with stent-like results is safe and effective in dialysis patients, and validates the clinical approach we used.

Cardiac deaths during follow up were more common in dialysis patients $(11 \% v 2 \%$ in non-dialysis patients). In 1974, Lindner and colleagues suggested that atherogenesis is accelerated in dialysis patients. ${ }^{25}$ However, if there is indeed accelerated atherogenesis it does not seem to be secondary to the dialysis itself. Half of all dialysis patients have evidence of coronary artery disease before the initiation of haemodialysis, ${ }^{26}$ and no correlation has been found between cardiac events and the duration of dialysis. ${ }^{12}$ The high prevalence of coronary artery disease in these patients seems to be related to numerous risk factors for atherosclerosis, including hypertension, diabetes, hypercoagulation, lipid abnormalities with hypertriglyceridaemia and decreased high density lipoprotein, and hyperhomocysteinaemia. ${ }^{27}$ In our study the rate of repeat revascularisation for disease progression was similar in dialysis and non-dialysis patients, which could be explained by the intensive treatment of coronary risk factors. The higher rate of cardiac deaths in dialysis patients may be related to cardiac disease linked to renal failure. Cardiac abnormalities in dialysis patients include the following:

- left ventricular hypertrophy explained by hypertension, hypovolaemia, sympathetic overactivity, and anaemia;

- interstitial myocardial fibrosis, related to increased secretion of parathyroid hormone;

- reduced myocardial perfusion reserve, related to structural and functional changes in intramyocardial arteries and to reduced capillary density;

- abnormalities of myocardial metabolism with abnormal control of intracellular calcium in cardiomyocytes, and impaired mitochondrial oxidation and glycolytic pathways. ${ }^{28}$

These microvascular and metabolic abnormalities reduce ischaemia tolerance and increase ventricular arrhythmias and cardiac deaths in dialysis patients, even in the absence of myocardial infarction.

However, our results after coronary stenting in dialysis patients are much better than those reported previously after balloon angioplasty and bypass surgery. In the series of 12271 revascularised dialysis patients reported by Herzog, ${ }^{4}$ the two year mortality was $47.2 \%$ for balloon angioplasty and $46.5 \%$ for surgery, while the two year cardiac event rate was $83.7 \%$ for angioplasty and $70 \%$ for surgery $(p<0.0001)$. Similar unfavourable results with balloon angioplasty and surgery have been reported in many single centre series..$^{5-11} \mathrm{~A}$ lower incidence of recurrent angina is reported after surgery, but there are no data to prove that surgery or balloon angioplasty improves survival in dialysis patients. ${ }^{6-9} 12$ The benefit of coronary stenting in this high risk population was also suggested in a recent report on patients identified in the US Renal Data System database. ${ }^{29}$ In this report, dialysis patients had a lower one year mortality after coronary stenting than after bypass surgery or balloon angioplasty performed before stenting facilities became available $(80.1 \%, 68.7 \%$, and $69.4 \%$ respectively)

\section{LIMITATIONS}

The rates of clinical restenosis in dialysis and non-dialysis patients were not significantly different $(31 \% v 28 \%)$. However, because of the small number of dialysis patients, there is a risk of $\beta$ error. As there was no systematic angiographic follow up in patients with 
negative non-invasive testing, there may be an underestimation of the angiographic restenosis rate. However, patients with angiographic restenosis but without myocardial ischaemia have the same long term medical care and prognosis as do those without restenosis. ${ }^{21}$

CONCLUSIONS

Coronary stenting in dialysis patients seems to decrease acute complications following coronary angioplasty with suboptimal results. In our study, dialysis was not a risk factor for clinical restenosis when coronary stenting was performed, or when stent-like results were obtained after balloon angioplasty. Thus coronary angioplasty seems to be a safe and effective therapeutic procedure in selected dialysis patients with culprit lesions accessible to stenting. However, the one year survival is lower in this high risk population. Clinical outcome after angioplasty can be improved by intensive treatment of coronary risk factors and routine non-invasive testing to detect restenosis or disease progression. Bypass surgery should be reserved for dialysis patients with severe angina refractory to medical treatment, extensive coronary artery disease inaccessible to stenting, and an acceptable surgical risk.

1 United States Renal Data System. Patient modality and survival. Am f Kidney Dis 1995;26:S69-84.

2 United States Renal Data System. Causes of death. Annual data report No 14. Bethesda, MD: The National Institute of Health, National Institute of Diabetes and Digestive and Kidney Disease, 1995:79-90.

3 Herzog CA, Ma JZ, Collins AJ. Poor long-term survival after acute myocardial infarction among patients on long-term dialysis. N Engl f Med 1998;339:799-805.

4 Herzog CA. Diagnosis and treatment of ischemic heart disease in dialysis patients. Curr Opin Nephrol Hypertens 1997; 6:558-65.

5 Schoebel FC, Gradaus F, Ivens K, et al. Restenosis after elective coronary balloon angioplasty in patients with end stage renal disease: a case-control study using quantitative coronary angiography. Heart 1997;78:337-42.

6 Ahmed WH, Shubrooks SJ, Gibson CM, et al. Complications and long-term outcome after percutaneous coronary angioplasty in chronic hemodialysis patients. Am Heart $\mathcal{f}$ 1994;128:252-5.

7 Rinehart AL, Herzog CA, Collins AJ, et al. A comparison of coronary angioplasty and coronary artery bypass grafting outcomes in chronic dialysis patients. Am $\mathcal{F}$ Kidney Dis $1995 ; 25: 281-90$

8 Kahn JK, Rutherford BD, McConahay DR, et al. Short- and long-term outcome of percutaneous transluminal coronary angioplasty in chronic dialysis patients. Am Heart $\mathcal{F}$ 1990;119:484-9.

9 Koyanagi T, Nishida H, Kitamura M, et al. Comparison of clinical outcomes of coronary artery bypass grafting and percutaneous transluminal coronary angioplasty in renal dialysis patients. Ann Thorac Surg 1996;61:1793-6.

10 Reusser LM, Osborn LA, White HJ, et al. Increased morbidity after coronary angioplasty in patients on chronic hemodialysis. Am f Cardiol 1994;73:965-7.

11 Marso SP, Gimple LW, Philbrick JT, et al. Effectiveness of percutaneous coronary interventions to prevent recurrent coronary events in patients on chronic hemodialysis. Am f Cardiol 1998;82:378-80.

12 de Lemos JA, Hillis DL. Diagnosis and management of coronary artery disease in patients with end-stage renal disease on hemodialysis. F Am Soc Nephrol 1996;7:2044-54.

13 Fischman DL, Leon MB, Baim DS, et al. A randomized comparison of coronary-stent placement and balloon angioplasty in the treatment of coronary artery disease. $N$ Engl f Med 1994;331:496-501.

14 Serruys PW, de Jaegere P, Kiemeniej F, et al. A comparison of balloon-expandable-stent implantation with balloon angioplasty in patients with coronary artery disease. $N E n g l$ f Med 1994;331:489-95.

15 Le Feuvre C. Angioplasty and stenting in patients with renal disease [editorial]. Heart 2000;83:7-8.

16 Le Feuvre C, Bonan R, Côté G, et al. Five- to ten-year outcome after multivessel percutaneous transluminal coronary angioplasty. Am 7 Cardiol 1993;71:1153-8.

17 Remuzzi G, Benigni A, Schieppati A, et al. Platelet function in patients on maintenance hemodialysis: depressed or in patients on maintenance hemodialys

18 Notohamiprodjo M, Andrassy K, Bommer J, et al. Dialysis membranes and the coagulation system. Blood Purif 1986: 4:130-41

19 The EPISTENT Investigators. Randomised placebocontrolled and balloon-angioplasty-controlled trial to assess safety of coronary stenting with use of platelet glycoprotein-IIb/IIIa blockade: evaluation of platelet IIb/ IIIa inhibitor for stenting. Lancet 1998;352:87-92.

$20 \mathrm{Ko}$ W, Kreiger K, Isom O. Cardiopulmonary bypass procedures in dialysis patients. Ann Thorac Surg 1993;55:667-

21 Le Feuvre C, Bonan R, Lespérance J, et al. Predictive factors of restenosis after multivessel percutaneous transluminal coronary angioplasty. Am f Cardiol 1994;73:840-4

22 Lafont AM, Dubois-Randé JL, Steg PG. The French optimal stenting trial (FROST): a multicenter, prospective randomized study comparing systematic stenting to angiography/coronary flow reserve guided stenting [abstract]. Circulation 1997;96:I-222.

23 Serruys PW, di Mario C, Piek J, et al. Prognostic value of intracoronary flow velocity and diameter stenosis in assessing the short- and long-term outcomes of coronary balloon ing balloon angioplasty trial Europe). Circulation 1997;96: 3369-77.

24 Seruys PW. Benestent II, a remake of Benestent I? Or a step towards the era of stentoplasty? Eur Heart $\mathcal{F}$ 1999;20:77981

25 Lindner A, Charra B, Sherrard D, et al. Accelerated atherosclerosis in prolonged maintenance hemodialysis. $N$ Engl f Med 1974;290:697-701.

26 Venkatesan J, Henrich WL. Cardiac disease in chronic uremia: management. Adv Renal Replac Ther 1997;4:24966.

27 Moustapha A, Naso A, Nahlawi M, et al. Prospective study of hyperhomocysteinemia as an adverse cardiovascular risk factor in end-stage renal disease. Circulation 1998;97:13841 .

28 Amann K, Ritz E. Cardiac disease in chronic uremia: pathophysiology. Adv Renal Replac Ther 1997;4:212-24.

29 Herzog CA, Ma JZ, Collins AJ. Comparative survival of dialysis patients in the United States after coronary artery bypass surgery, coronary angioplasty, and coronary stenting [abstract]. Circulation 1998;98:78.

\title{
Narrative Based Medicine, An Interdisciplinary Conference
}

\author{
Research, Narrative, and Practice
}

\section{A two day conference-Monday 3rd and Tuesday 4th September 2001}

\section{Homerton College, Cambridge, UK}

\section{BMF Publishing Group}

For full details contact: BMA/BMJ Conference Unit, Tavistock Square, London, WC1H 9JP Tel: +44 (0)207383 6819; fax: +44 (0)207383 6663; email: clyders@bma.org.uk.

www.quality.bmjpg.com 